the degree of mixing between the $1 / 2+$ and $3 / 2+$ bands.

So far it has not been possible to calculate the mixing parameters $m_{1}$ and $m_{2}$, but the model may be tested by using the experimental values of $B(\mathrm{E} 1)$ for two transitions to determine $m_{1}$ and $m_{2}$, and then to use these values to calculate the $B(E 1)$ values for the other transitions. Pilt did this for the transitions in ${ }^{23} \mathrm{Na}$, and found that the reduced transition rates for the whole band are very well given by this model. The same analysis was applied. to the transitions in ${ }^{21} \mathrm{Na}$, and this also gave good overall agreement with the data, although it did not have such a simple pattern as that for ${ }^{23} \mathrm{Na}$.

An attempt to calculate the mixing parameters from the Nilsson model was not successful; it was found that there is no value of the nuclear deformation that gives the observed distribution of transition strengths. It thus seems that a more detailed microscopic theory is needed to obtain a proper understanding of these quantities.

Even in its present form, with the parameters treated as adjustable and fitted to the data for each nucleus, the model can be very useful in correlating experimental data, and it could well be a useful method of determining the spins of high-spin states. It would clearly be useful to test its applicability to other nuclei, and this might show some systematic behaviour of the mixing parameters, which in turn might provide a clue to their microscopic interpretation.

\section{A tribe of mimics}

\section{From a Correspondent}

BLENNIES are generally known as small, rather retiring fishes living in shallow water close to rocks or coral. Very many species are known in temperate and tropical seas but the latter contains the greatest number of species. A few are found in freshwater. Partly because there are so many nominal species, ichthyologists were exercised in attempting to assess their phylogeny, and for long the standard work on the group as a whole was J. R. Norman's provisional synopsis (Ann. Mag. nat. Hist., ser. 11, 10, 793-812; 1943). More recently, V. G. Springer's study of the osteology and classification of the family (Bull. U.S. natn. Mus. 284, $1-85$; 1968) has provided a major clarification and a useful overall classification within which Springer, and others, can tackle the smaller groups in the family.

The most recent is a revision of the sabre-toothed blennies of the tribe Nemophini by W. F. Smith-Vaniz (Acad! natn. Sci. Philadelphia, Monogr.

\title{
Origin of North China loess
}

from I. J. Smalley

CHINESE civilisation developed on the great North China loess deposits. Ho (Cradle of the East, Chicago University Press, 1975) has argued convincingly that this development took place in isolation, uninfluenced by the parallel progress in the Middle East. A major factor which did influence the growth of the early Chinese civilisation was the presence of the loess which was an ideal soil for the early farmers. The origin of this North China loess is still in dispute. Most of the other loess deposits in the world have glacial connections and their formation can be seen as part of a sequence of Pleistocene events, but the Chinese loess does not have an obvious glacial link.

The results of the first electron microscope observations of Chinese loess have now been published ( $\mathrm{Lu}$ et al. Geochimica 47, 1976). These allow the Chinese workers to reject totally the Berg theory of in situ formation, but they still find themselves unable to accept totally a direct glacial connection. The grains observed are broken and have sharp edges, and silica precipitation and chemical etching are commonly observed on the quartz silt particles, which might have been subjected to relatively long weathering processes

19, 1-196; 1976); an excellent contribution to the systematics of these Indo-Pacific blennies. As a taxonomic work it is of fundamental importance for not only are 41 species in 5 genera fully described and figured, but 13 of these species are new taxa, recognised here for the first time. However, this paper is important not just because it is a highly competent revision, but because of the information about the life styles and behavioural relationships of this fascinating group of blennies.

The sabre-toothed blennies are so called because they all have a massive recurved canine tooth postericrly in the lower jaw. Most species also have smaller caniniform teeth in the upper jaw. In the front of both jaws the teeth are small, closely-packed and incisiform. Such dentition suggests that their feeding behaviour might be specialised, an expectation which is fully realised.

Members of the genus Meiacanthus are unique among fishes in having welldeveloped toxic buccal glands. Their sabre teeth are grooved, the groove leading to the gland in the dentary bone and acting as a channel for the pale, toxic secretion. All the species of Meiacanthus bite when attacked, and before being transported to the loess accumulation areas. In the relevant areas the authors suggest that glaciation only occurred on mountain tops, and that this may have produced some loess, but they favour a distant western source for the majority of the material. No specific particle-producing mechanism is described.

It may be that in this case a longer than usual transportation stage was involved and that material was formed in distant glaciated regions and that the continuing aridity and the presence of mixed particle deposits in the post-Pleistocene times prevented the formation of stable loess deposits. In Europe and North America loess deposits form very close to the ice limits. The Lu et al. paper is an encouraging sign of the renewal of interest in loess sedimentology in China. It is a pity that those otherwise admirable data handlers, Science Citation Index and Mineralogical Abstracts, have not realised that in Chinese the family name (as used in references) comes first; so this important paper has been listed under Yanchou et al. which could cause some confusion.

I. J. Smalley is a lecturer in the Department of Civil Engineering at the University of Leeds.

experiments have shown that they are generally unacceptable as prey although naive fish predators may take them into their mouth, only to spit them out quickly. In ecology and behaviour they differ strikingly from most blennies. They inhabit open water and in daytime forage over a wide area in search of small crustaceans in the water column, and tend to hover in one spot then jerk away, to hover again, feeding as they pause.

Their virtual immunity from predators no doubt has a bearing on their behaviour and it is not surprising that several species are brilliantly coloured in life. Various Meiacanthus species have close mimics, including unrelated fishes, as well as other sabre-toothed blennies.

The latter include several species of Plagiotremus which hover and jump in much the same way as the Meiacanthus model. The former feed on larger fishes, especially non-predatory ones, hovering nearby and then launching a lightning attack on the passing fish, usually from the rear. If the prey turns head-on suddenly the attack will be aborted. Their incisor teeth are curved, sharp in the horizontal plane, but flattened in the lateral, are well adapted 